\title{
Outcome of the acellular dermal matrix and split thickness skin graft in release of post burn contractures in hand.
}

1. MBBS, FCPS

Assistant Professor Plastic Surgery

D.G. Khan Medical College,

D.G. Khan.

2. MBBS, FCPS

Assistant Professor Plastic Surgery Holy Family Hospital, Rawalpindi.

3. MBBS, FCPS

Associate Professor Plastic Surgery Jinnah Burn and Reconstructive Surgery Center, Lahore.

4. MBBS, FCPS

Senior Registrar Plastic Surgery Jinnah Burn and Reconstructive Surgery Center, Lahore.

5. MBBS

Medical Officer/ Post Graduate Resident Plastic Surgery Jinnah Burn and Reconstructive Surgery Center, Lahore.

6. MBBS, FRCS, FCPS

Professor Plastic Surgery

Jinnah Burn and Reconstructive

Surgery Center, Lahore.

Correspondence Address:

Dr. Abdul Malik Mujahid

Department of Plastic Surgery

D.G. Khan Medical College, D.G. Khan. iqbalian_127@yahoo.com

Article received on:

$11 / 03 / 2020$

Accepted for publication:

08/07/2020

\section{INTRODUCTION}

Although, the contribution of hands to body surface area is only three percent, the overall functional outcome is the key in rehabilitation of involved hand. American Burn Association (ABA) has clearly described the hand injury as one of the major injury. ${ }^{1}$ In addition, there is $50-60$ percent loss of function if both hands are affected ${ }^{2,3}$ In thermal injuries, hand is most commonly involved structure presenting more than two third percentage of the cases. ${ }^{4,5}$ Even small areas of burn can interfere adversely with the hand functions. Specific age groups represent specific pattern of hand burns. The infants usually sustain deep dermal or full thickness burns from flame or heat as they cannot protect themselves. Scald
Abdul Malik Mujahid', Husnain Khan², Yawer Sajjad ${ }^{3}$, Kashif Mehmood Sheikh ${ }^{4}$, Noor Ali ${ }^{5}$, Moazzam Nazeer Tarar ${ }^{6}$

ABSTRACT... Objective: To determine the frequency of success of acellular dermal matrix obtained from all the patients. Pre-operative photography was done to compare the post-operative results. After the release of contractures, coverage with acellular dermis and plit thickness skin graft was performed. All the patients were followed up to 2 months and the (a) presented as frequencies and percentages. Results: Mean age of patient was $30 \pm 9$ years. Among them 40 were males and 35 females. Vancouver scale showed successful outcome praft a very reliable option for coverage after release of post-burn contractures in hand as it provides very pliable, thin and lax skin with good color match and better contour to surrounding Key word:

Acellular Dermal Matix, Post-burn Contractures, Split Thickness Skin Graft, Vancouver Scar Scale. acellular dermal matrix and split thickno skin graft in rease of post bu contractures in hand. Professional Med J 2021; 28(2):147-152. https://doi.org/10.29309/TPMJ/2021.28.02.4646

burns is another cause that affect this group of patients. This accidental type of burn mostly effects dorsal surface of hand. Adult population most commonly suffers flame burn involving the dorsal surface as hands are used as a protective tool for other body parts especially face. People tend to close their fists as a protective mechanism that usually spare the palm.

The depth of burn is dependent on thickness of skin. Palm, having glabrous skin which is thicker than dorsum skin which has high healing capacity and heals quite well spontaneously. The dorsum of hand is covered by very thin and mobile skin and tends to have deeper burn as compared to palm. Subsequently, there are high chances of 
exposure of deeper structures in this area which usually require soft tissue coverage. One of classic burn is from electric injury that can damage the deeper muscles and tendons which eventually leads to fixed flexion deformity of hand and wrist. In Western countries, electric burn injuries accounts for three to seven percent of total burn cases but this value rises up to $18-20 \%$ in developing countries. Upper limb is usually involved in 70 to 88 percent of all high voltage electric injuries. ${ }^{6,7}$ The magnitude of this devastating injury can be estimated by the fact that it is fifth leading cause of death in occupational accidents. ${ }^{7}$

Early and aggressive management of hand is important to preserve the function of hand and to achieve best possible outcome. Standard of care in burn management is that early closure of burn wound can minimizes edema, reduce pain and promote earlier functional rehabilitation. Thus, it is considered as key component to longterm outcome with respect to hand function. Several studies have reported coverage of hand burns with skin grafts. However, widely meshed grafts forces wound healing to occur through re-epithelialization that can result in wound contraction and hypertrophic scars. ${ }^{8}$ In a study, Pensler et $\mathrm{al}^{9}$ reported that there is no difference in STSG versus FTSG in terms of functional outcome. However Schwanholt et $\mathrm{al}^{10}$, later on observed improved hand function and decreased need for secondary procedures by use of FTSG for the treatment of acute deep palmar burns in children.

Delay in coverage or inadequate skin coverage of the burned hand can lead to the development of unstable scars and complications of scar contractures or hypertrophy ${ }^{11}$ The exposure of vital structures such as tendons or nerves poses a separate problem. In such circumstances, pedicled flaps or free tissue transfer offer a better solution for coverage of hand defects. These options may be unavailable in patients surviving large TBSA burns and can be associated with bulky flap with aesthetically poor results, tissue mismatch, two stage procedure and donor site morbidity. These limitations have stimulated the search for alternative methods of resurfacing.
Tissue expansion has gained some attention in this regards. ${ }^{12}$ Unfortunately; this technique is not without its own disadvantages.

Skin substitutes and acellular dermal matrix have long been of interest in coverage of acute burn patients. Clinical studies have reported that skin substitutes may heal well with less scarring than conventional skin grafts. Acellular dermal matrix is human cadaveric allograft which is obtained after the process of removal of dermis, decullularization of dermis and matrix preservation by soaking in cryoprotectant. Key components of this include intact collagen fibrils, elastin, vacular channels, proteoglycan and basement membrane. These component helps to provide tensile strength, elasticity, initiation of revascularization and support of epithelial surface in grafts. Acellular dermal matrix acts as a vascularized bed over which split thickness skin graft is well taken. ${ }^{14}$ The advantages of ADM are that it confers good healing and pliability, with functional and cosmetic benefits similar to those of FTSG but without comparable potential for donor-site morbidity. Another property which offers advantages in hand surgery is its ability to retain collagen and elastin fibers after undergoing decellularization and sterilization. ${ }^{15}$ After its application, the wound site skin is supple and flexible and does not adhere to the deeper structures, thus permitting free articular and functional movement approaching the normal skin contour. ${ }^{16,17}$ In a study conducted in 2010, the scar function of 14 patients, who underwent dermal substitution with acellular dermal matrix in burns and post-burn contracture corrections at 15 sites were assessed by using the vancouver scar scale. This study showed that 10 scar sites $(86 \%)$ had vancouver scar scale score of 4 or less. ${ }^{18}$

We conducted a study to determine the success of acellular dermal matrix and split thickness skin grafting in post burn contracture release in hand by using Vancouver Scar Scale. As no local data is available, however, this is internationally proven and data shows variability in this regard, so this study will set a baseline data in Pakistan. Secondly, this will be considered as primary result which is suitable for patients having post 
burn contractures which are relatively difficult to be managed in terms of routine procedures and for patients who are unable to be treated with free tissue transfer because of other co-morbidities.

\section{MATERIAL \& METHODS}

A descriptive case series was conducted at Plastic Surgery Department, Jinnah Burn and Reconstructive Surgery Center, Lahore from $1^{\text {st }}$ March, 2019 to $30^{\text {th }}$ October, 2019. Sample size of 75 cases was calculated with $95 \%$ confidence level, $10 \%$ margin of error and taking expected $86 \%$ good outcome i.e. Vancouver Scale Scar Score of 4 or less out of total 13 score. Sampling was done through non probability consecutive sampling. Patients who full filled the inclusion criteria (Age 01-80 years, Both gender, Patients having post burn contractures in hand determined clinically and size approximately (range $1-10 \mathrm{~cm}$ length,1-6 cm width) were included in the study). Patients with history of poly trauma, diabetes mellitus, hypertension and bleeding disorders were excluded from the study. After the approval from hospital ethical committee, informed consent was obtained from all the patients. Patient's contracture was assessed in detail and was stratified according to the site. Preoperative photography was done to compare the postoperative results. After adequate contracture release under tourniquet control, acellular dermal matrix was placed and secured, followed by split thickness skin graft over ADM. First dressing change was done on $7^{\text {th }}$ post-operative day. If uneventful, patients were discharged on $7^{\text {th }}$ post-operative day. All patients were followed up after one week of discharge in outpatient department and then after 2 months. Outcome variable were assessed by using Vancouver Scar Scale. The collected data was entered and analyzed by using SPSS version 20. Descriptive statistics were calculated. Quantitative variables like age, size of scar were presented as mean, \pm standard deviation. Qualitative variables gender and success were presented as frequencies and percentages.

\section{RESULTS}

In this study, a total of 75 patients were recruited from Jinnah Burn and Reconstructive Surgery
Center Lahore. The selected patients were in the age range of 2 to 57 years. Most of the patients were in the $2^{\text {nd }}$ and $3^{\text {rd }}$ decade of life. Mean and standard deviation was recorded as $30+9.78$. Out of 75 patients, 40 were male and 35 were female. 10 were having contracture of PIPJ, 8 have DIPJ contracture, 14 have MCPJ contracture, and 16 were of wrist and 27 of them having combined type of contracture. (Table-I). Complete graft take and primary healing was achieved in 49 cases. There was partial necrosis of skin graft in 22 cases and complete loss 4 case. 53 cases were having score less than 4 and 22 were having score more than 4. Complications including hematoma, infection, compromised distal vascularity and partial release of contracture were studied. Hematoma at recipient site was found in 2 cases. Infection was seen in 3 cases. There was no sign of compromised distal vascularity in any of the case. 4 cases were complicated by partial release of contracture (Table-II).

\begin{tabular}{|l|c|c|}
\hline \multicolumn{1}{|l|}{ Variables $\mathbf{n = 7 5}$} & Frequency & Percentage \\
\hline Age (In Years) & Mean & $\mathbf{3 0 + 9 . 7 8}$ \\
\hline $12-29$ & 33 & 44.0 \\
\hline 30 and above & 42 & 56.0 \\
\hline Gender & & \\
\hline Male & 35 & 47.0 \\
\hline Female & 40 & 53.0 \\
\hline Site of Contracture & & \\
\hline PIP & 27 & 36.0 \\
\hline DIP & 16 & 21.0 \\
\hline MCP & 14 & 19.0 \\
\hline Wrist & 11 & 13.0 \\
\hline Combined & 4 & 11.0 \\
\hline
\end{tabular}

Table-I. Demographic and clinical profile of patients

\begin{tabular}{|c|c|c|}
\hline Variables $n=75$ & Frequency & Percentage \\
\hline \multicolumn{3}{|l|}{ Graft Take } \\
\hline Complete Take & 49 & 65.3 \\
\hline Partial Loss & 22 & 29.3 \\
\hline Complete Loss & 4 & 5.4 \\
\hline \multicolumn{3}{|c|}{ Outcome (Vancouver Scare Scale) } \\
\hline$<4$ & 53 & 70.6 \\
\hline$>4$ & 22 & 29.4 \\
\hline \multicolumn{3}{|c|}{ Complications $\mathrm{n}=\mathbf{9}$} \\
\hline Hematoma & 2 & 2.7 \\
\hline Infection & 3 & 4.0 \\
\hline $\begin{array}{l}\text { Partial Release of } \\
\text { Contracture }\end{array}$ & 4 & 5.3 \\
\hline \multicolumn{3}{|c|}{ Table-II. Outcome among patients } \\
\hline
\end{tabular}




\section{DISCUSSION}

Reconstructive surgery is a challenge not only in the large and complex defects but also for smaller and technically simple looking defects. The soft tissue loss may be accompanied by injury to underlying nerves, tendons and bones. Although Soft tissue coverage is the main concern but functional outcome must be taken into consideration of the injured hand. The basic principle of replacing like with like must be kept in mind. Unfortunately, in variety of injuries, there is concomitant trauma to adjacent tissues which makes these options unavailable in such circumstances. In these scenario, tissues from distant areas is the available. In case of established contractures that involve the underlying structures of hand, usually there is paucity of the adjacent tissue. During release of such major contractures, there is a risk of exposing the tendons, joints or other vital structures like neurovascular bundle. If exposed, these structures have to be resurfaced with thin, pliable and well vascularized tissue in form of distant flaps and free tissue transfer, but it can result in aesthetically unpleasant outcome due to its bulkiness and donor site morbidity.

This problem is overcome by use of acellular dermal matrix along with thin split thickness skin graft. The acellular dermal matrix acts as a vascularized bed for the take of the graft. The pliability and stability of the resurfaced skin is attributable to the fact that the dermal matrix retains the elastin and collagen components after the decellularization. Literature shows that the dermal matrix provides thin, supple and pliable soft tissue. It has least tendency for adhesion formation and thus allows free and easy joint mobility and tendon excursion under the reconstructed surface. It also provides good quality skin over reconstructed tissue along with decreased incidence of future scaring and contractures.

When flaps are not feasible and faced with potentially salvageable injured hands and fingers, thin and meshed acellular dermal matrix may provide durable and vascularized soft tissue coverage while minimizing eventual deformities. ${ }^{19}$ In 2008 Dhaval Bhavsar et al published a study that reported the use of thin and meshed acellular dermal matrix to cover the exposed joint, tendon, and neurovascular bundle. Of twenty six digits treated in four patients, 19 digits demonstrated supple and durable skin coverage with acceptable joint mobility. Askari $\mathrm{M}$ et al conducted a study on nine patients with burn scars contracture involving different locations in the hand and the wrist. All the patients retained at least eighty three percent of the corrected range of motion of affected joints by 1 year. They concluded that acellular dermal matrix can be an effective modality in management of difficult burn contracture deformity in the hand, with long lasting results. ${ }^{20}$ Our study results are comparable to the said study in terms of rage of motion and pliability.

In 2012 Ellis CV ${ }^{21}$ and Kulber DA publish a literature review of more than hundred articles published between 1994 and 2011. They concluded that clinical indications for acellular dermal matrix have increased throughout the last 15 years. Juhasz et al, collected data on 18 patients who had previously received acellular dermal implant alloderm. The age of these patients were in range of 16 months to 84 years. Among those, fifteen implant sites of 14 patients were assessed with average area of the implants $185 \mathrm{~cm}^{2}$. The scar function was assessed by using the modified Vancouver Scar Scale and they observed that overall scar function and quality was significantly betteronimplantedareas thanoverthesurrounding scarred skin. Their findings suggested that acellular dermal implants are especially useful tools in the treatment of full thickness burns as well as post burn scar contractures. ${ }^{22}$ We enrolled total 75 patients, out of which 40 $(53 \%)$ were male and 35 (47\%) were female who have post burn contractures of hand. Wrist and MCPJ contracture were more common. This data showed that there are more incidences of injuries in physically active people. As males are more prone to injury at their work places, they are the most effected people. Most of the people presenting in 12 to 30 years of age had burn incidence in their childhood. Any they developed contractures due to lack of attention and physiotherapy.

All patients underwent release of contracture 
under tourniquet control and the defect was resurfaced with accellular dermal matrix followed by thin STSG. There was complete take of graft in $49(86.6 \%)$ cases, while partial loss was seen in $22(8 \%)$ cases. When analyzed retrospectively, we found the partial loss of graft in those cases where large area was resurfaced. All the patients were treated conservatively and none of them required secondary procedure. Patients were also assessed with Vancouver scar scale. There was a major difference of the groups that lie below or above score of 4 . Fifty three $(70.66 \%)$ patients had scored less than 4 . While only 22 (29.33\%) cases had score greater than 4 . This shows a significant improvement in the overall scar qualities of soft tissue after the release of contracture and coverage with acellular dermal matrix and split thickness skin graft

\section{CONCLUSION}

During reconstruction, both the functional as well as aesthetic aspects must be kept in mind. Acellular dermal matrix followed by split thickness skin graft is a reliable and suitable option for the coverage of defects after the release of post burn contractures in the hand, as it provides thin, pliable and durable skin coverage that has good color and contour match with the surrounding tissue. It shares all the advantages of any fasciocutaneous flap without the drawbacks of bulkiness and donor site morbidity.

\section{CONFLICT OF INTEREST}

Authors have no financial or personal interests with any people or organisation that would influence this work

Copyright@ 08 July, 2020.

\section{REFERENCES}

1. American Burn Association. Guidelines for service standards and severity classifications in the treatment of burn injury. Bull Am Coll Surg. 1984; 69: 24-29.

2. American Medical Association. Guides to the evaluation of permanent impairment, 4th ed., Chicago. American Medical Association. Upper Extremity burn reconstruction. Mathes and Nahai. 1994; vol 7 chap 186:p 604.
3. Engrav LH, Dutcher KA, Nakamura DY. Rating burn impairment. Clin Plast Surg 1992; 19: 569-598.

4. Helm PA. Burn rehabilitation: Dimensions of the problem. Clin Plast Surg. 1992; 19: 551-9.

5. Harvey KD et al. Computer-assisted evaluation of hand and arm function after thermal injury. $J$ of Burn Care and Rehab. 1996; 17: 176-80.

6. Hansen TB, Carstensen $\mathrm{O}$. Hand injuries in agricultural accidents. J Hand Surg. 1999; 24 (B):190 -2.

7. Chase RA. Costs, risks and benefits of hand surgery. J Hand Surg. 1983; 8(A): 644-8.

8. Hansbrough JF, Franco ES. Skin replacements. Clin Plast Surg 1998; 25:407-423.

9. Pensler JM, Stewart R, Lewis SR, Herndon DN. Reconstruction of the burned palm, full thickness vs. Split thickness skin grafts-long-term follow up. Plast Recon Surg 1988; 81: 46-49.

10. Schwanholt C, Greenhaigh DG, Warden G.A Comparison of full thickness versus split thickness auto grafts for coverage of deep palmar burns in the very young pediatric patient. J Burn Care Rehab 1993; 14:29-33.

11. Whitson TC, Allen BD. Management of the burned hand. J Trauma1971; 11:606.

12. Pisarski GP et al. Tissue expander complications in pediatric burn patient. Plast Recons Surg 1998; 102: 1008-1012.

13. Hergrueter CA, O'Connor NE. Skin substitutes in upper extremity burns. Hand Clin.1990; 6: 239-242.

14. Askari M, Cohen MJ, Grossman PH, Kulber DA. The use of acellular dermal matrix in release of burn contracture scars in the hand. Plast Reconstr Surg. 2011 Apr; 127(4):1593-9.

15. Ellis CV, Kulber DA. Acellular dermal matrices in hand reconstruction. Plast Reconstr Surg. 2012 Nov; 130 (5 Suppl 2):256S-69S.

16. Chen S, Tzeng $Y$, Wang C. Treatment of severe burn with DermACELL, an acellular dermal matrix. Int $\mathrm{J}$ Burn Trauma 2012; 2(2):105-109.

17. Pan Y, Liang Z, Yuan S, Xu J, Wang J, Chen S. A longterm follow-up study of acellular dermal matrix with thin auto graft in burns patients. Ann of Plas Surg. October 2011; 67(4):346-351. 
18. I. Juhasz, B. Kiss, L. Lukacs, I. Erdei, Z. Peter, and E. Remenyik. "Long-Term followup of dermal substitution with acellular dermal implant in burns and post burn scar corrections," Dermatology Research and Practice 2010; p: 1-4.

19. Dhaval Bhavsar, Mayer Tenehaus. The use of acellular dermal matrix for coverage of exposed joint and extensor mechanism in thermally injured patients with few options. Eplasty 2008; 8: e33.

20. Askari M, Cohen MJ, Grossman PH, Kulber DA. The use of acellular dermal matrix in release of burn contracture scars in the hand. Plast Reconst Surg. Apr 2011; 127(4): 1593-9.
21. Ellis CV, Kulber DA. Acellular dermal matrices in hand reconstruction. Plast Reconst Surg. 2012 Nov; 130 (5 Suppl 2): 256S-69S.

22. Juhasz I, Kiss B, Lukacs L, Erdei I, Peter Z, Remenyik E. Long-term followup of dermal substitution with acellular dermal implant in burns and postburn scar corrections. Dermatology research and practice. 2010 Jan 1;2010.doi: 10.1155/2010/210150. Epub 2010 Dec 30. PMID: 21234359; PMCID: PMC3018619.

\begin{tabular}{|c|c|c|c|}
\hline \multicolumn{4}{|c|}{ AUTHORSHIP AND CONTRIBUTION DECLARATION } \\
\hline Sr. \# & Author(s) Full Name & Contribution to the paper & Author(s) Signature \\
\hline 1 & Abdul Malik Mujahid & $\begin{array}{l}\text { Principal contributor, Concep- } \\
\text { tualization and design of rese- } \\
\text { arch work, data collection. }\end{array}$ & A \\
\hline 2 & Husnain Khan & $\begin{array}{l}\text { Data collection, statistical } \\
\text { analysis, interpretation of data. }\end{array}$ & \\
\hline 3 & Yawer Sajjad & $\begin{array}{l}\text { Writing of manuscript, results } \\
\text { analysis. }\end{array}$ & Yaiil \\
\hline 4 & Kashif Mehmood Sheikh & $\begin{array}{l}\text { Drafting, literature search, Data } \\
\text { collection, final approval. }\end{array}$ & $\ln c_{1}^{c}$ \\
\hline 5 & Noor Ali & $\begin{array}{l}\text { Literature search, statsitical } \\
\text { analysis revision of manuscript. }\end{array}$ & U2k \\
\hline 6 & Moazzam Nazeer Tarar & $\begin{array}{l}\text { Drafting, Review of results and } \\
\text { final approval }\end{array}$ & \\
\hline
\end{tabular}

